Document downloaded from:

http://hdl.handle.net/10251/83242

This paper must be cited as:

Bosholm, F.; López Navarro, A.; Gamarra, M.; Corberán Salvador, JM.; Payá Herrero, J. (2016). Reproducibility of solidification and melting processes in a latent heat thermal storage tank. International Journal of Refrigeration. 62:85-96. doi:10.1016/j.ijrefrig.2015.10.016.

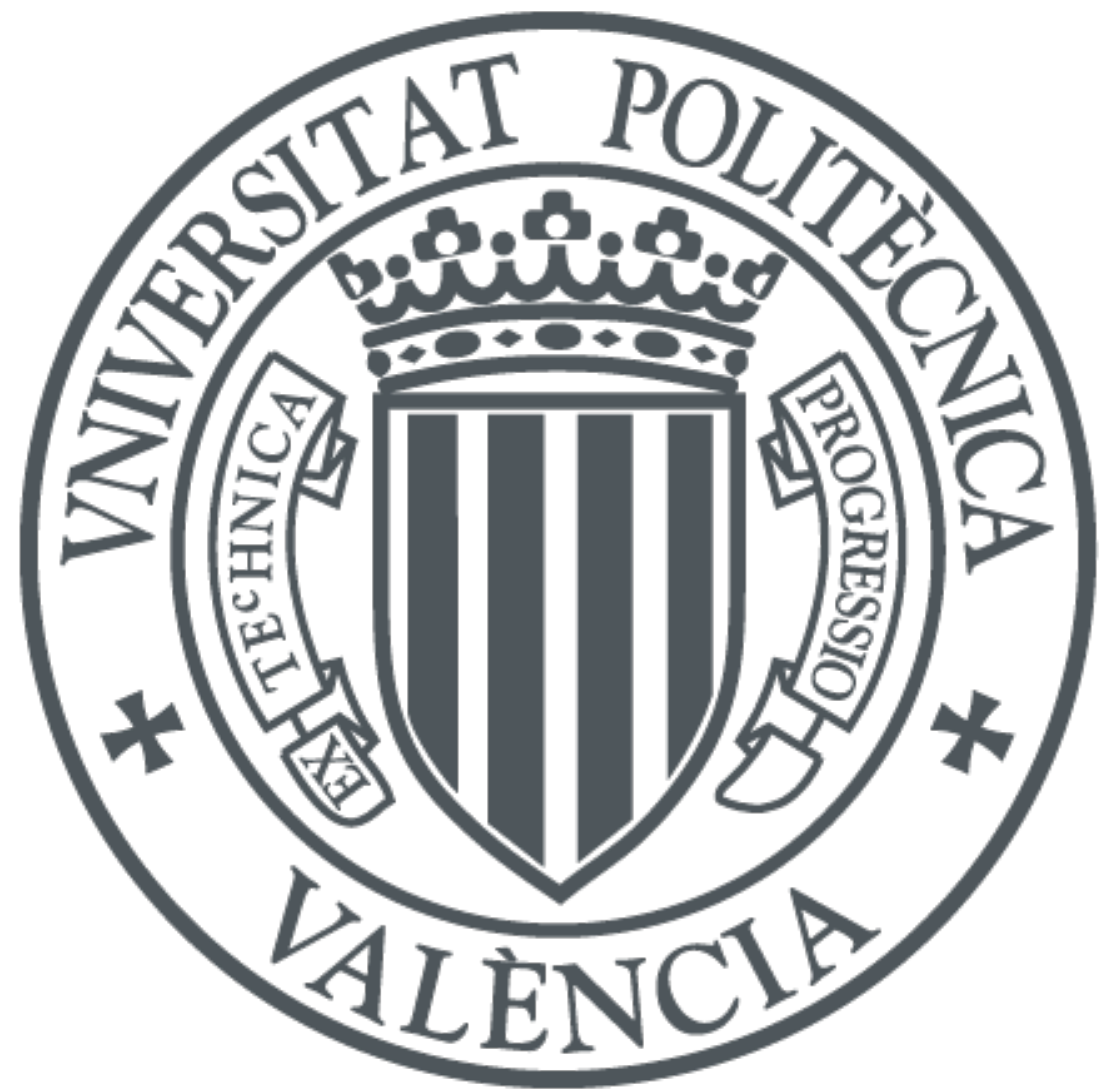

The final publication is available at

http://doi.org/10.1016/j.jirefrig.2015.10.016

Copyright Elsevier

Additional Information 


\title{
Reproducibility of solidification and melting processes in a latent heat thermal storage tank
}

\author{
F. Bosholma , A. López-Navarroa , M. Gamarra ${ }^{a}$, J.M. Corberána, J. Payáa, \\ ${ }^{a}$ Instituto de Ingeniería Energética IIE, Universitat Politècnica de València \\ Camino de Vera s/n, Edificio 8E cubo F 5 a planta, 46022 Valencia, Spain
}

\begin{abstract}
This study analyses the reproducibility of solidification and melting tests in a tank containing $181 \mathrm{~kg}$ of paraffin for cold storage at around $8^{\circ} \mathrm{C}$. Firstly, an experimental campaign of 10 identical tests was carried out. The performance is practically the same in terms of PCM temperatures and thermal power, with a maximum deviation of $2 \%$ in the capacity of all tests. In a second campaign, the impact of the initial conditions was studied. The results indicate that fixing a same mean PCM temperature at the beginning of the tests is insufficient to ensure an accurate reproducibility. Depending on the heat transfer rate during the preparation tests, the capacity differed in up to $33 \%$. In tanks with such quantities of PCM, fixing a uniform initial PCM temperature is hardly possible, thus it is important to prepare the tank with same operation conditions.
\end{abstract}

Keywords: thermal energy storage tank, PCM, paraffin, experimental, reproducibility

${ }^{*}$ Corresponding author. Tel.: +34 963879910; Fax: 34 963877272;

E-mail address: jorpaher@iie.upv.es (J. Payá) 


\begin{tabular}{|llll|}
\hline NOMENCLATURE & & \\
$\dot{m}$ & Mass flow rate, $\mathrm{kg} \mathrm{s}^{-1}$ & $\mathrm{~T}$ & Temperature, ${ }^{\circ} \mathrm{C}$ \\
$\mathrm{C}_{\mathrm{p}}$ & Specific heat, $\mathrm{J} \mathrm{kg}^{-1} \mathrm{~K}^{-1}$ & $\dot{Q}$ & Thermal power, $\mathrm{W}$ \\
$\mathrm{E}$ & Energy, $\mathrm{J}$ & $\mathrm{t}$ & Time, $\mathrm{s}$ \\
Abbreviations / subscripts & & \\
TES & Thermal Energy Storage & LHS & Latent Heat Storage \\
PCM & Phase Change Material & SHS & Sensible Heat Storage \\
supply & Inlet temperature of the tank & return & Return temperature of the tank \\
HTF & Heat Transfer Fluid & init & Initial conditions \\
RST & Reproducible Solidification Test & NRST & Non Reproducible Solidification Test \\
RMT & Reproducible Melting Test & NRMT & Non Reproducible Melting Test \\
\hline
\end{tabular}

\section{Introduction}

The research in latent heat thermal storage systems has been very active in recent years, from the synthesis and characterization of phase-change materials (PCMs) to a full system level. This increasing activity can be understood from an energy and economical context (Azeldin et al., 2014; Yun et al., 2011; Saman, 2013) such as the climate change, the rising energy prices and the higher penetration of renewables in the energy mix.

Residential and commercial buildings present a high contribution to the worldwide energy consumption among other reasons for air-conditioning (Chua et al., 2013). The peak demand of electricity is actually growing faster than the total use of electricity (Newsham and Bowker, 2010), and in many countries the prices in on-peak and offpeak periods are significantly different. In this context, cold storage is an interesting solution given that it is considered to be cheaper than electricity storage (Mac Cracken, 2010).

PCMs have been used for decades for load shifting (Brousseau and Lacroix, 1996; Saito, 2002). Available cold storage technologies have been reviewed (Hasnain, 1998; Oró et al., 2012), addressing both sensible and latent heat storage. Water as PCM is cheap and has very good thermo-physical properties even on a long term. Another option is using ice-slurries, for instance Kauffeld et al. provided an overview for a wide range of applications (Kauffeld et al., 2005, 2010).

The use of ice storage with respect to other PCMs is a compromise between the investment cost of the tank and the energy efficiency of the installation. The energy efficiency in HVAC systems is particularly hindered because of the low temperatures 
required for the solidification (Sehar et al., 2012; Beghi et al., 2014; Rismanchi et al., 2012). PCMs with higher melting temperatures than ice/water can increase the energy savings, for example Bruno et al. obtained savings of around $13.5 \%$ with a melting temperature in the PCM of $10{ }^{\circ} \mathrm{C}$ (Bruno et al., 2014). Given that the chilled water temperature of a conventional air-conditioning system is typically supplied at $7{ }^{\circ} \mathrm{C}$, there is a significant interest in PCMs with a phase-change temperature in the range of $5-10^{\circ} \mathrm{C}$ (Farid et al., 2004).

Paraffins are an interesting option for cold storage given their commercial availability, relatively high melting enthalpy and a good cyclic behavior. Recent advances aim to enhance the thermal conductivity, to increase the phase-change enthalpy or to obtain cheaper PCMs (Peñalosa et al., 2014).

On a practical basis, literature on tanks with a significant capacity remains relatively scarce (Gil et al., 2014; Banaszek et al., 1999; Tay et al., 2012). Most of this published work involves a characterization of the tank performance depending on the operation conditions (e.g. mass flow rates, supply temperatures) but the initial conditions are generally presented very briefly, and they usually consist in fixing a same mean PCM temperature in the tank.

Paraffins are known to have a stable cyclic behavior in specific setups with small samples. However, in tanks with a significant PCM capacity, the determination of a unique initial state is not straightforward due to the low thermal conductivity, to the buoyancy effect and to the long periods which are necessary to ensure a full solidification or melting in PCM. Therefore, the scientific question which arises is if the tank performance is reproducible, rather than if the PCM is thermodynamically stable after many cycles.

This work has a direct link with practical cold storage installations, where the operation strategies have to be designed to ensure a correct performance of the tank. A simple solution can be to determine the state of the tank using PCM temperature sensors. However, the present study indicates that the heat transfer rate at which the charging is done has a significant impact on the thermal storage performance.

To the authors' knowledge, on a tank level, no studies have been carried out to demonstrate if the tests are perfectly reproducible when executed under identical operation conditions, and to quantify the impact of the initial state on the tank's thermal energy storage. The present results indicate that having a same mean PCM temperature in the beginning of the tests is insufficient to ensure a perfect reproducibility, particularly in tanks with dead volumes where small temperature fluctuations around the phase-change temperature can have a significant impact in the measured thermal energy storage capacity

\section{Material and methods}

\subsection{Experimental set-up}

The LHS tank was built and tested at the Polytechnic University of Valencia. In a recent publication (López-Navarro et al., 2014) the experimental set-up, the instrumentation and the experimental uncertainties were described in detail. Thus, the present section focuses on providing the basic data of the tank and in describing the test procedure. 
As indicated in Fig. 1, the tank has an internal heat exchanger which consists of 8 spiral-shaped coils placed in counter flow. The 8 coils are connected with 4 vertical collectors, two in the center and two in the external part of the tank. In total, the heat exchanger has a surface of $5.75 \mathrm{~m}^{2}$ in contact with the PCM. This coil design presents the disadvantage of having a low heat transfer surface in contact with the PCM but it helps to reach a significant storage capacity with a relatively cheap heat exchanger, already available for instance in ice-storage solutions. Filling the tank with a hydrated salt would theoretically lead to a higher capacity, although on a long term the PCM stability or corrosion problems could appear.

The tank contains $181 \mathrm{~kg}$ of the paraffin RT8 (Rubitherm, 2014). According to T-history measurements, the phase-change mainly takes place in the temperature range from 3 to $8{ }^{\circ} \mathrm{C}$ The total enthalpy variation from 0 to $15^{\circ} \mathrm{C}$ is $176 \mathrm{~kJ} \mathrm{~kg}^{-1}$ (Rubitherm, 2014). This provides a maximum theoretical capacity of $31.8 \mathrm{MJ}$.

The LHS tank contains 18 T-Type thermocouples to monitor the PCM temperatures. As indicated in Fig. 1, each thermocouple is defined by a position $T_{i j}$. The subscript $i$ corresponds to a horizontal row and $j$ is a vertical column. Note that the thermocouples $\mathrm{T}_{\text {i6 }}$ are positioned in the center of the tank and the others in the spiral heat exchanger region or "active" zone. The dead central region is unavoidable using the spiral-shaped coil concept given that the copper tubes have a maximum curvature.
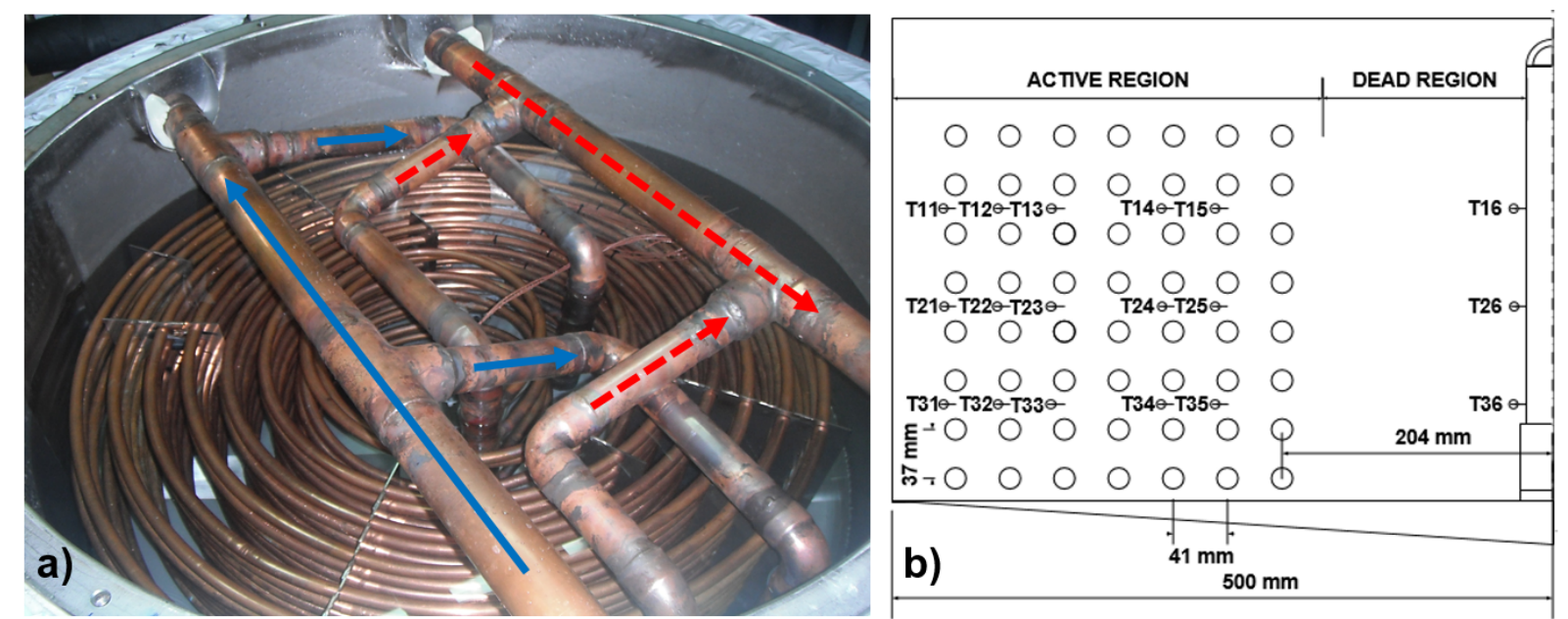

Fig. 1. Position of thermocouples inside the LHS tank

The thermocouples $T_{i 5}$ are situated close to a vertical collector and hereby the heat transfer is increased with respect to the adjacent columns. The heat transfer fluid (HTF) inside the coils consists of a $32 \%$ mass mixture of ethylene - glycol / water. The supply and return temperatures outside the LHS tank were measured with RTD thermal resistances PT100 1/10DINB. 


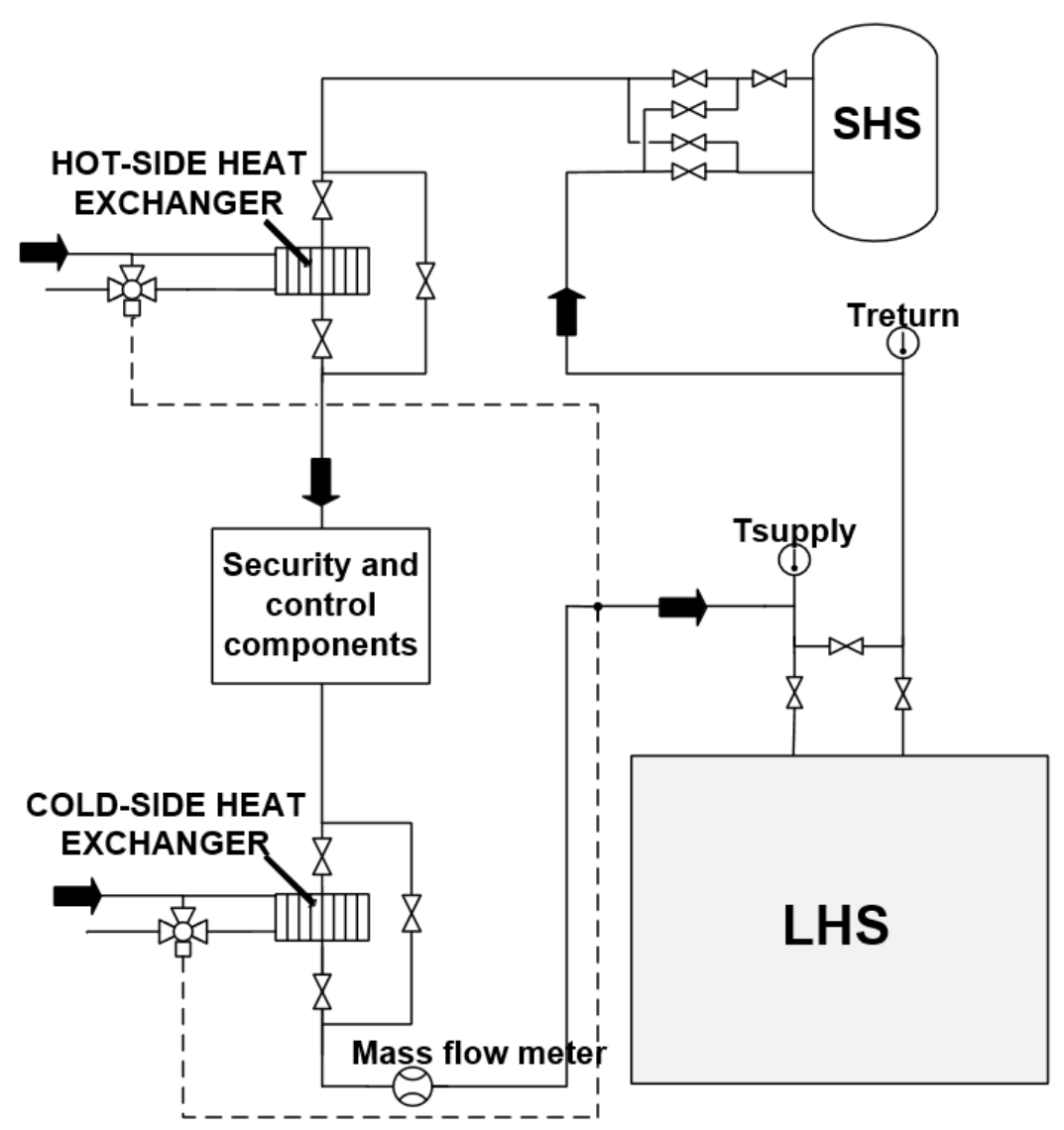

Fig. 2. Layout of the full experimental test rig

From the point of view of the control in the tests, it is important to highlight that a 1000 I sensible heat storage (SHS) tank was placed downstream of the LHS tank, as illustrated in Fig. 2. The main purpose of the SHS is to dampen the impact of the high thermal power at the beginning of the tests. The combination of the SHS and the heating/cooling circuits have helped to achieve a constant supply temperature of the HTF within $\pm 0.3 \mathrm{~K}$ of the set-point temperature. The mass flow rate is practically held constant too within a band of $\pm 30 \mathrm{~kg} / \mathrm{h}$. In the tested conditions the HTF was always in laminar flow (López-Navarro et al., 2014).

\subsection{Objectives of the experimental campaigns}

In order to compare tests, for instance with different operation conditions, it is essential to start with a same PCM temperature.. Firstly, the PCM temperature has to be prepared to the desired initial value, and secondly, the HTF has to reach the target setpoint of the test.

The first experimental campaign (sections 3.1 and 3.2) aims to determine if the tests are reproducible when prepared and executed identically. The second campaign (sections 3.3 and 3.4) shows different preparation strategies and their impact on the performance. 


\section{Results and discussion}

\subsection{Reproducible solidification tests (RST)}

The RST campaign was prepared by heating the LHS tank with a supply temperature of $12.5^{\circ} \mathrm{C}$ and a mass flow rate of $2000 \mathrm{~kg} / \mathrm{h}$ sufficiently long enough until all PCM thermocouples reach $12.5^{\circ} \mathrm{C} \pm 1 \mathrm{~K}$ (liquid state). As discussed in a recent study on the same tank (López-Navarro et al., 2014), the vertical temperature stratification in the PCM, especially in the liquid phase, cannot be avoided and therefore the target was to achieve a maximum deviation of $1 \mathrm{~K}$ with respect to the supply temperature.

Once the target PCM temperature is reached, the LHS is by-passed and the SHS tank which is downstream is prepared with the target supply temperature of $-1^{\circ} \mathrm{C}$. As soon as this temperature is reached, the tests start by communicating the LHS tank with the HTF.

Table 1 provides the initial mean PCM temperature, the average supply temperature and average mass flow rate throughout the solidification tests. Additionally the arithmetic mean and standard deviation are given.

Fig. 3 shows the power and energy (left and right y-axis respectively) exchanged by the HTF and calculated as expressed in Eqs. (1-2) based on the enthalpy variation. The high gradient shown at the beginning of the tests can be explained by the high temperature difference between the HTF $\left(-1^{\circ} \mathrm{C}\right)$ and the PCM $\left(\sim 13^{\circ} \mathrm{C}\right)$. Owing to the SHS tank which is downwards of the LHS tank, even during the first minutes the supply temperature can be held constant.

Table 1. Operation conditions in the RST tests

\begin{tabular}{lccc}
\hline & $\overline{\boldsymbol{T}}_{\text {PCM,init }}\left({ }^{\circ} \boldsymbol{C}\right)$ & $\overline{\mathbf{T}}_{\text {Supply }}\left({ }^{\circ} \boldsymbol{C}\right)$ & $\overline{\dot{\boldsymbol{m}}}_{\boldsymbol{H T F}}\left(\frac{\boldsymbol{k g}}{\boldsymbol{h}}\right)$ \\
\hline RST 1 & 11.9 & -0.91 & 2000 \\
RST 2 & 12.2 & -0.95 & 1997 \\
RST 3 & 12.5 & -0.96 & 1999 \\
RST 4 & 11.8 & -0.97 & 1999 \\
RST 5 & 12.1 & -1.01 & 2001 \\
RST 6 & 12.4 & -0.96 & 2001 \\
RST 7 & 12.2 & -0.98 & 1997 \\
RST 8 & 12.1 & -1.00 & 1998 \\
RST 9 & 12.2 & -1.02 & 1998 \\
RST 10 & 12.2 & -1.00 & 2000 \\
\hline$\overline{\boldsymbol{x}}_{\text {arith }}$ & 12.2 & -0.98 & 1999 \\
$\boldsymbol{\sigma}_{\overline{\boldsymbol{x}}}$ & 0.20 & 0.03 & 1.4 \\
\hline
\end{tabular}




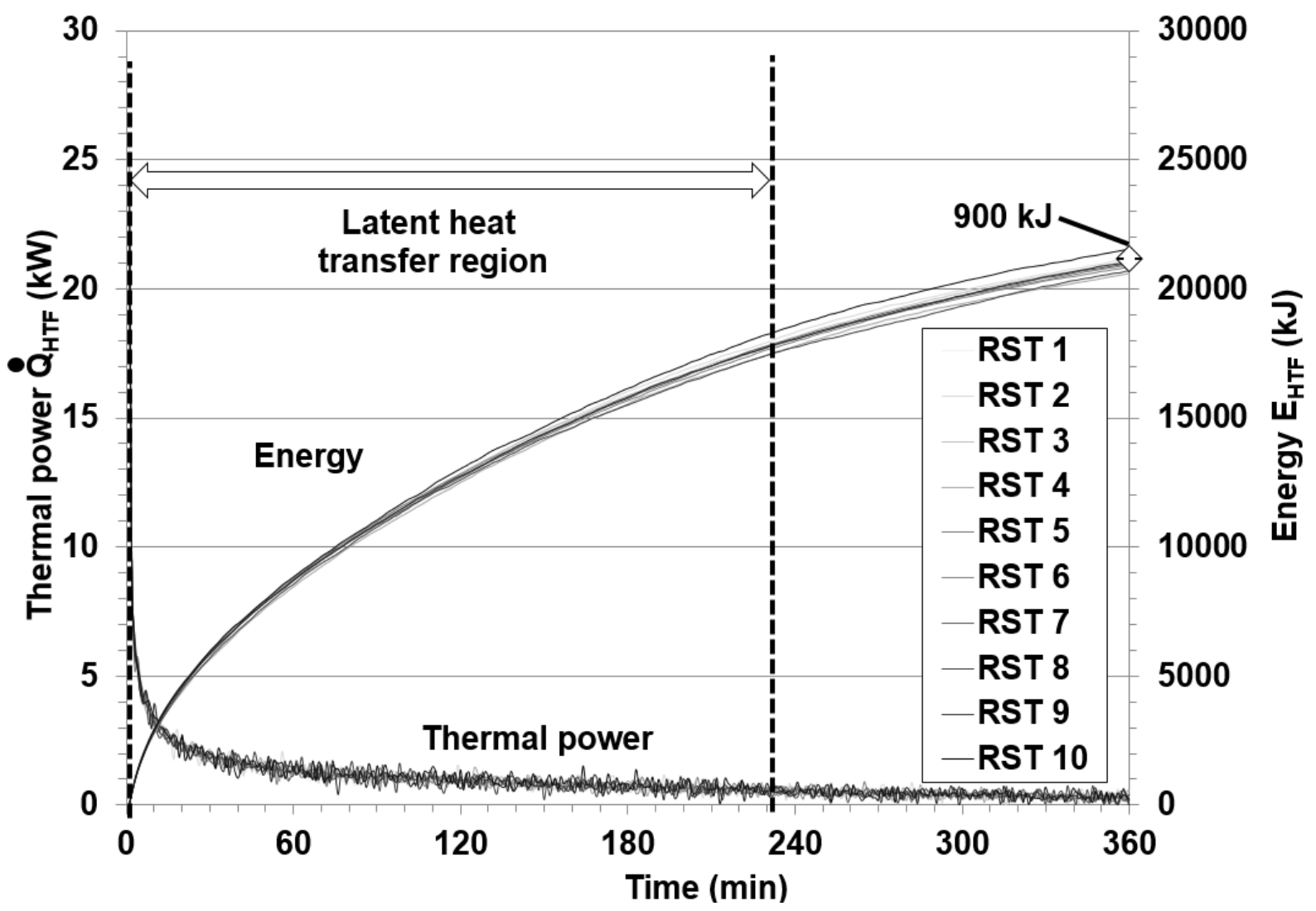

Fig. 3. Thermal power and energy transfer in the RST tests

$$
\begin{gathered}
\dot{Q}_{H T F}(t)=\dot{m}_{H T F} \cdot c_{p, H T F} \cdot\left|T_{\text {supply }}-T_{\text {return }}\right| \\
E_{H T F}(t)=\int_{0}^{t} \dot{Q}_{H T F} \cdot d t
\end{gathered}
$$

The latent heat transfer region for each test has been defined arbitrarily as the time interval where the mean PCM temperature is in the temperature range $1-11^{\circ} \mathrm{C}$. This criterion is only an estimation of the latent heat transfer region, given that the enthalpytemperature curves of the PCM depend on the heat transfer rate, and that there are internal PCM temperature differences within the tank.

The latent heat transfer region accounts for around $82 \%$ of the total energy transfer and is exchanged in $63 \%$ of the duration of the RST tests. The measured energy transfer at the end of the RST tests presents a mean value of $21.0 \mathrm{MJ}$ with a very small standard deviation of $288 \mathrm{~kJ}$.

Fig. 4 shows the temperature profiles in the middle row, for thermocouples $\mathrm{PCM}_{13}$, $\mathrm{PCM}_{23}, \mathrm{PCM}_{33}$ that are situated in active area and for thermocouple $\mathrm{PCM}_{26}$ which is located in the center of the tank. The heat transfer in this region of the tank is not sufficiently effective to induce a full phase-change, as shown by thermocouple $\mathrm{PCM}_{26}$. In a practical usage, this region acts as a dead mass (López-Navarro et al., 2014) since the phase-change is too long with typical operation conditions. In fact, the maximum energy transfer in Fig. 3 is far from the maximum capacity of the tank (31.8 $\mathrm{MJ})$. 
Very similar temperature profiles on the same tank were presented and discussed in recent work (López-Navarro et al., 2014) and thus the present study focuses on the reproducibility of the tests rather than on the interpretation of the temperature trends.

As shown in Figs. 3-4, the RST tests are practically identical despite having inevitable deviations of $\pm 0.03 \mathrm{~K}$ in the average supply temperature, $\pm 1.4 \mathrm{~kg} / \mathrm{h}$ for the mean mass flow rate and $\pm 0.2 \mathrm{~K}$ in the initial PCM temperature.

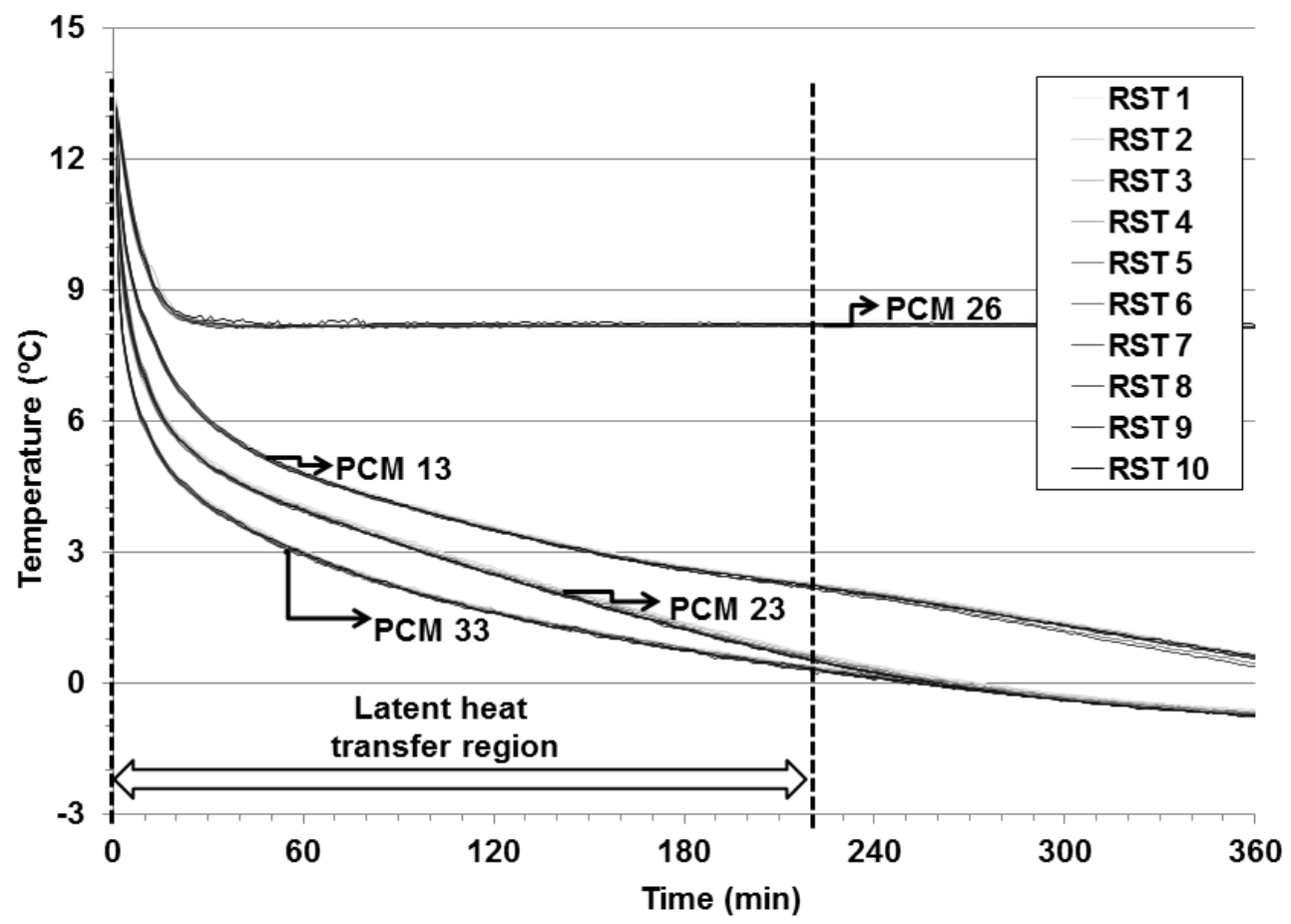

Fig. 4. PCM temperature in the RST tests

3.2 Reproducible melting tests (RMT)

In order to perform the RMT tests, a previous solidification was carried out with a supply temperature of $-1^{\circ} \mathrm{C}$ and mass flow rate of $2000 \mathrm{~kg} / \mathrm{h}$. All RMT tests started with a sufficiently long solidification for all 18 PCM thermocouples to reach a temperature of $1{ }^{\circ} \mathrm{C} \pm 1 \mathrm{~K}$.

After the initial state of the tank was prepared, all RMT tests were performed with a supply temperature of $13^{\circ} \mathrm{C}$ and a mass flow rate of $2000 \mathrm{~kg} / \mathrm{h}$. Table 2 shows the initial conditions of the RMT tests. Note that RMT 10 starts with an initial mean PCM temperature of $1.77^{\circ} \mathrm{C}$ which is a difference of almost 3 times the standard deviation from the mean PCM temperature. As discussed in the following paragraphs, this leads to small differences in the PCM temperatures but with hardly any impact on the thermal power. 
Table 2. Operation conditions in the RMT tests

\begin{tabular}{lccc}
\hline & $\overline{\boldsymbol{T}}_{\boldsymbol{P C M}, \text { init }}\left({ }^{\circ} \boldsymbol{C}\right)$ & $\overline{\boldsymbol{T}}_{\text {Supply }}\left({ }^{\circ} \boldsymbol{C}\right)$ & $\overline{\dot{\boldsymbol{m}}}_{\boldsymbol{H T F}}\left(\frac{\boldsymbol{k g}}{\boldsymbol{h}}\right)$ \\
\hline RMT 1 & 1.06 & 12.96 & 2016 \\
RMT 2 & 0.82 & 13.01 & 2006 \\
RMT 3 & 0.96 & 13.01 & 1996 \\
RMT 4 & 0.96 & 12.94 & 2005 \\
RMT 5 & 1.00 & 13.01 & 2014 \\
RMT 6 & 1.15 & 12.99 & 2005 \\
RMT 7 & 1.06 & 12.94 & 2006 \\
RMT 8 & 0.99 & 13.01 & 2006 \\
RMT 9 & 0.90 & 13.03 & 2004 \\
RMT 10 & 1.77 & 13.02 & 1996 \\
\hline$\overline{\boldsymbol{x}}_{\boldsymbol{a r i t h}}$ & 1.07 & 12.99 & 2005 \\
$\boldsymbol{\sigma}_{\overline{\boldsymbol{x}}}$ & 0.25 & 0.03 & 6.0 \\
\hline
\end{tabular}

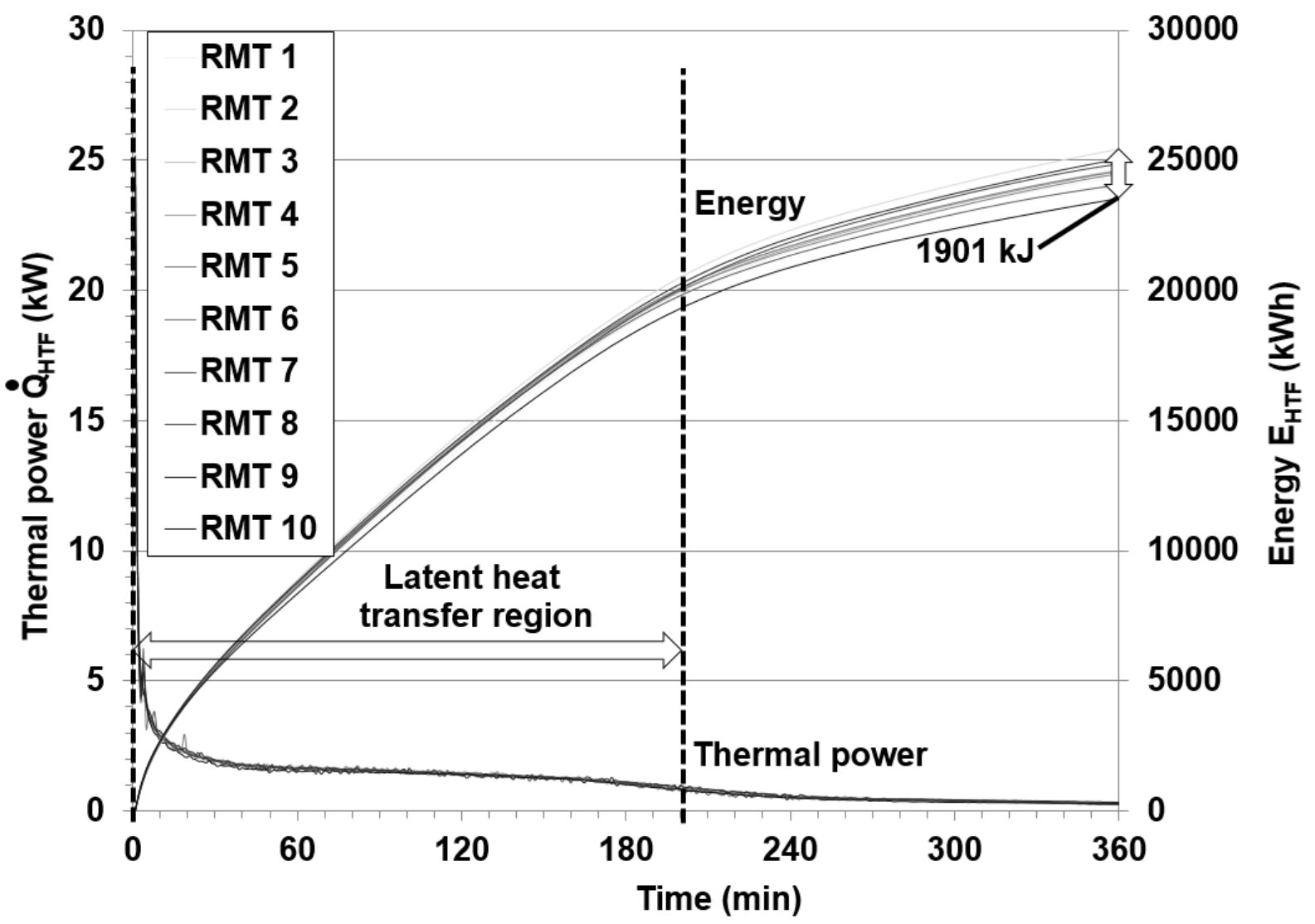

Fig. 5. Thermal power and energy transfer in the RMT tests

Fig. 5 illustrates the power and energy which is exchanged in the RMT tests. The latent heat transfer region takes place during $51 \%$ of the time and corresponds to $76 \%$ of the 
final capacity. The energy transfer is almost identical in all RMT tests despite the inevitable deviations of $\pm 0.03 \mathrm{~K}$ in the average supply temperatures, $\pm 1.4 \mathrm{~kg} / \mathrm{h}$ in the mass flow rate and $\pm 0.25 \mathrm{~K}$ in the initial PCM temperature. The arithmetic mean energy transfer is $24.6 \mathrm{MJ}$ with a standard deviation of $504 \mathrm{~kJ}$. Although this value is small with respect to the measured capacity, it is nevertheless around two times greater than for the solidification tests given the difficulty in fixing a unique initial state when the PCM is solid and has a low thermal conductivity.

In Fig. 6 the temperature profiles of $\mathrm{PCM}_{13}, \mathrm{PCM}_{23}, \mathrm{PCM}_{33}$ and $\mathrm{PCM}_{26}$ are displayed. At the beginning of the tests only the paraffin in the coil region ( $\left.\mathrm{PCM}_{13}, \mathrm{PCM}_{23}, \mathrm{PCM}_{33}\right)$ is affected. Given that the temperature profiles were discussed in a recent study (López-Navarro et al., 2014), the present section focuses on the differences between the 10 RMT tests.

Until the end of the latent heat transfer region is reached, there are only minor differences in the thermocouples. The sinking period, which is where solid blocks of paraffin detach from the upper coils and sink towards the bottom of the tank, is a good indicator for the end of the latent heat transfer process. This sinking period can be observed by a decrease of temperature in the lower regions $\left(\mathrm{PCM}_{33}\right)$ which receive the solid blocks, and by an increase in the upper regions $\left(\mathrm{PCM}_{13}\right)$ which collect the rising, warm and liquid paraffin.

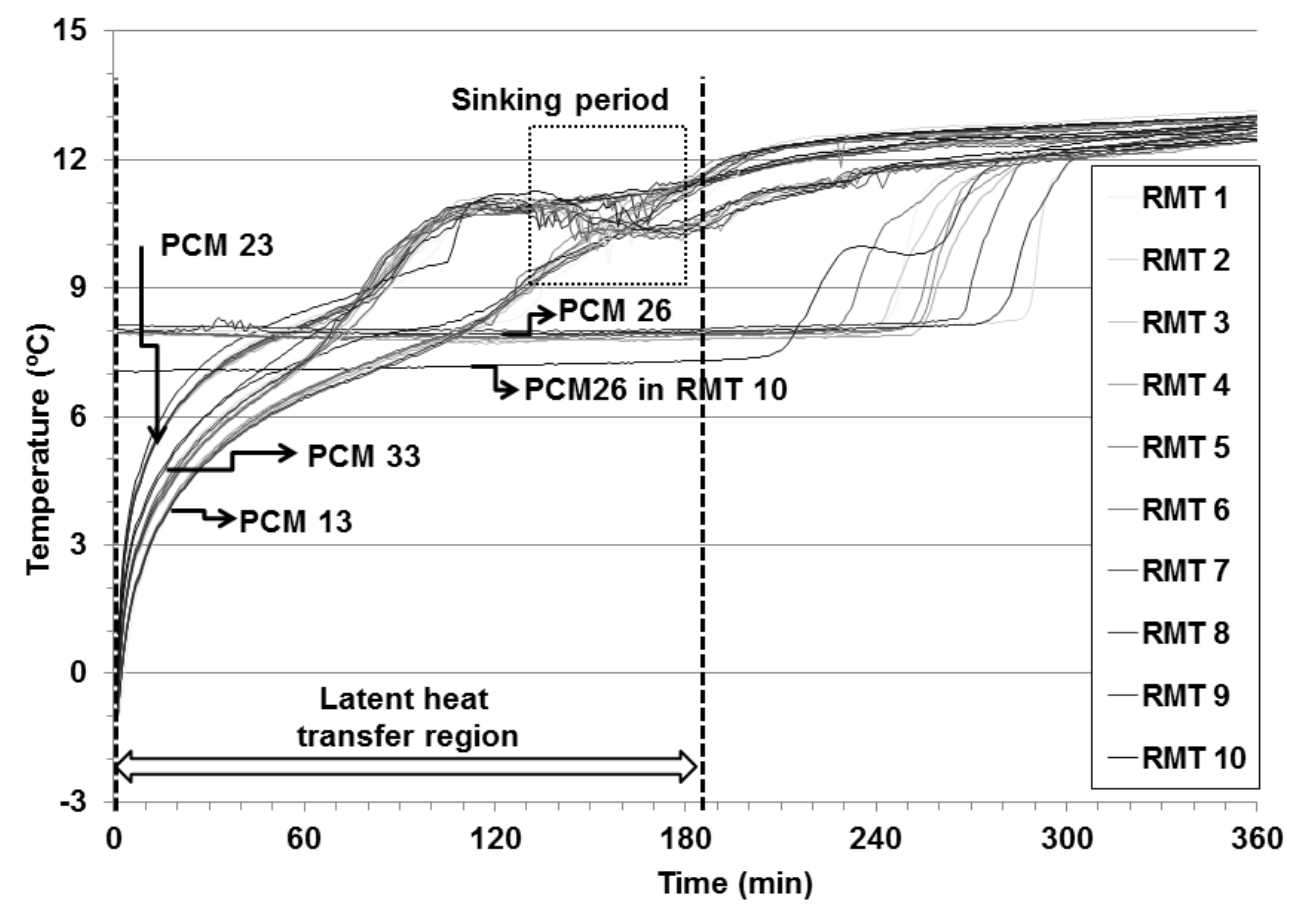

Fig. 6. PCM temperature in the RMT tests

The most relevant difference between the 10 tests is observed after the end of the latent heat transfer region, and more particularly in the center of the tank, which takes longer to increase its temperature. Test RMT 7 is the first to change phase in the central region, but there is around 60 minutes delay with respect to the slowest test (RMT 2). In any case, these local differences in the center of the tank do not have any impact on the thermal power and energy transfer (Fig. 5). 
Test RMT 10 presents more differences with respect to the other RMT tests, as can be observed for instance in $\mathrm{PCM}_{26}$ of Fig. 6 . The reason for this is that the initial state was slightly different to the other tests, as also noted before in Table 2. Nevertheless, from a macroscopic point of view, in terms of the thermal power and the measured capacity (Fig. 5) this does not have any noticeable impact.

\subsection{Non reproducible solidification tests (NRST)}

This section shows the effect of carrying out solidification tests with identical operation conditions (supply at $-4{ }^{\circ} \mathrm{C}$ and $2000 \mathrm{~kg} / \mathrm{h}$ ) and a same initial PCM temperature, but with a different supply temperature during the previous melting process.

Fig. 7 shows the detailed operation procedure of the NRST tests, which start in point A with a $\mathrm{PCM}$ temperature of $0^{\circ} \mathrm{C} \pm 1 \mathrm{~K}$ in the active area of the tank. The preparation (previous melting) is named Prep. 1 (slowest heating rate, $\mathrm{T}_{\text {supply }}=13^{\circ} \mathrm{C}$ ), Prep. 2 $\left(\mathrm{T}_{\text {supply }}=15^{\circ} \mathrm{C}\right.$ ) and Prep. 3 (fastest heating rate, $\mathrm{T}_{\text {supply }}=17^{\circ} \mathrm{C}$ ).

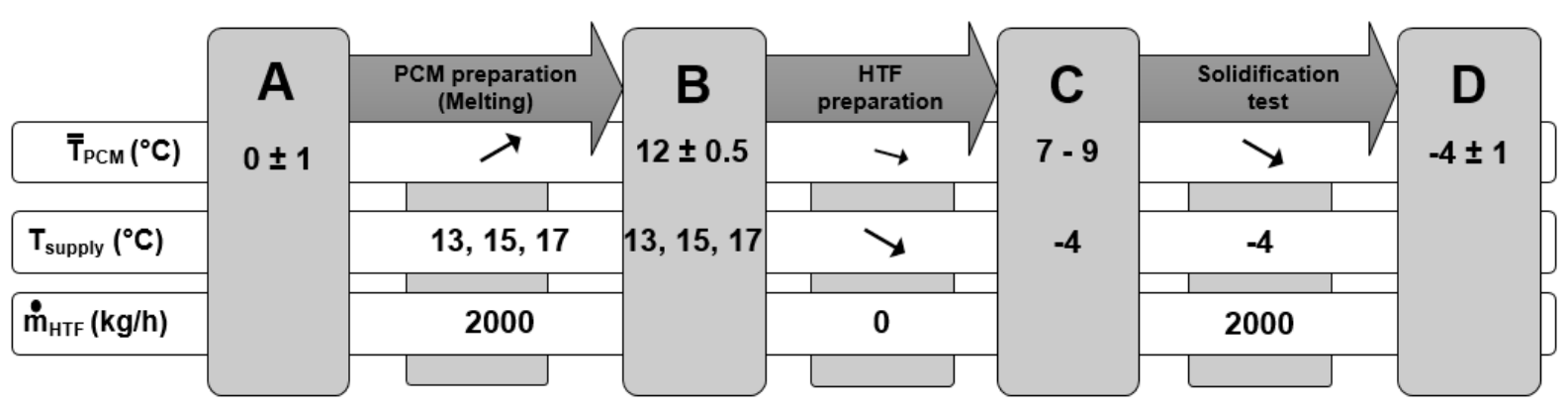

Fig. 7. Operation procedure in the NRST tests

The melting process $(A \rightarrow B)$ was stopped in point $B$ with a mean PCM temperature of $12{ }^{\circ} \mathrm{C} \pm 0.5 \mathrm{~K}$ in the active area. The SHS tank was then prepared between $\mathrm{B}$ and $\mathrm{C}$ until the target supply temperature of $-4{ }^{\circ} \mathrm{C}$ was reached. From $\mathrm{C}$ onwards the solidification period was performed until in $D$ the active PCM reached a temperature of $-4^{\circ} \mathrm{C} \pm 1 \mathrm{~K}$. A higher tolerance of $\pm 1 \mathrm{~K}$ has been applied in point $\mathrm{D}$ because of the low thermal conductivity of the paraffin, whereas in liquid state (point B) the PCM temperatures are more homogenous within a temperature band of $\pm 0.5 \mathrm{~K}$.

Table 3 shows more detailed information on the HTF and the active PCM not only during the solidification process $(C \rightarrow D)$ but also during the full preparation of the tests. Despite having a similar PCM temperature in $\mathrm{B}$, the beginning of the solidification process (point $\mathrm{C}$ ) for preparation 3 starts with a lower PCM temperature because of the different heating rate in $A \rightarrow B$.

The complete thermal history of the 3 tests in terms of PCM temperature and energy exchange is represented in Fig. 8. The solid lines represent the mean PCM temperature (left y-axis) whereas the dashed lines represent the energy exchange (right $y$-axis). The time reference ( 0 minutes) has been chosen for the beginning of the solidification process (point $\mathrm{C}$ ). 


\begin{tabular}{lcccc}
\hline $\begin{array}{l}\text { Table 3. Thermal history } \\
\text { of the NRST tests }\end{array}$ & Measurement & Prep. 1 & Prep. 2 & Prep. 3 \\
\hline Point A & $\bar{T}_{P C M}\left({ }^{\circ} \mathrm{C}\right)$ & 0.11 & -0.65 & 0.51 \\
PCM preparation A $\rightarrow$ B & $\bar{T}_{\text {Supply }}\left({ }^{\circ} \mathrm{C}\right)$ & 12.98 & 14.93 & 16.98 \\
Point B & $\bar{T}_{P C M}\left({ }^{\circ} \mathrm{C}\right)$ & 11.99 & 12.12 & 11.91 \\
Point C & $\bar{T}_{P C M}\left({ }^{\circ} \mathrm{C}\right)$ & 8.94 & 8.31 & 7.26 \\
Solidification test C $\rightarrow$ D & $\bar{T}_{\text {Supply }}\left({ }^{\circ} \mathrm{C}\right)$ & -3.99 & -4.05 & -4.00 \\
Point D & $\bar{T}_{P C M}\left({ }^{\circ} \mathrm{C}\right)$ & -3.65 & -3.71 & -3.70 \\
\hline
\end{tabular}

Although the solidification test $C \rightarrow D$ was executed with same operation conditions, the results show that the energy gain of the HTF ranges from $5.0 \mathrm{kWh}$ (Prep. 3) up to 6.6 kWh (Prep. 1). With respect to Prep. 1, the fastest preparation (3) leads to a solidification $(C \rightarrow D)$ which is $32 \%$ faster and with $25 \%$ less energy transfer. These differences are directly related to the preparation $(A \rightarrow B)$, which is $73 \%$ faster and with $33 \%$ less energy transfer.

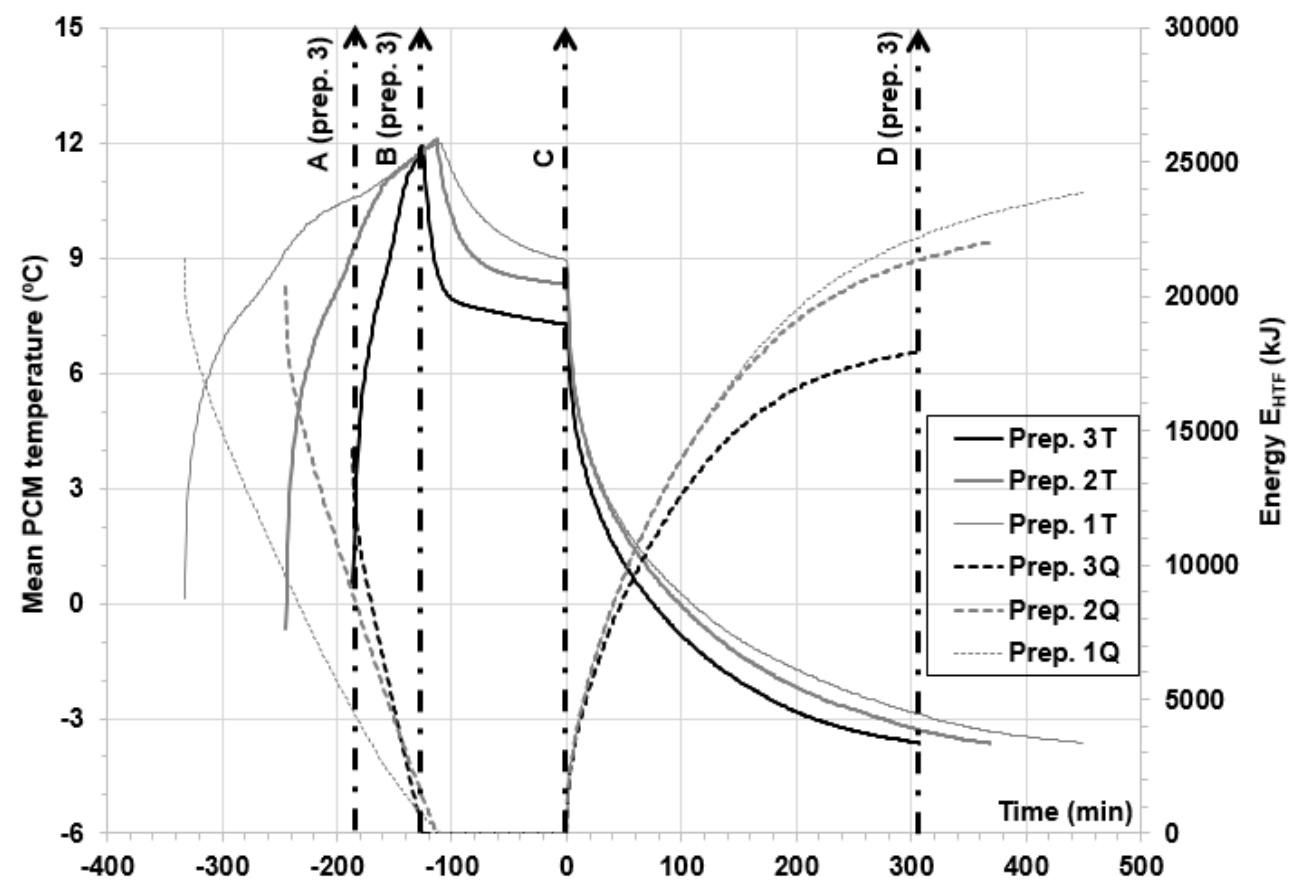

Fig. 8. PCM temperatures and energy transfer in the NRST tests 
Step $B \rightarrow C$ typically takes around one hour and during this time the PCM thermocouples indicate a temperature decrease (Fig. 8). Given that the tank was bypassed in $B \rightarrow C$, it can only be due to internal mass and energy transfer within the $\mathrm{PCM}$. A key point is to highlight that the $18 \mathrm{PCM}$ thermocouples in Fig. 1 are all in the same $\pi$ plane. In point $B$, despite having a same mean PCM temperature with the 3 preparations, the overall state of the tank is different as supported by the analysis of the radial PCM temperature distribution (Fig. 9). In fact, the fastest preparation in A $\rightarrow B$ (Prep. 3) leads to higher internal stratifications of temperature.

Fig. 9 presents the radial PCM temperatures throughout the full thermal history from A to $D$. The vertical axis represents the temperature and the horizontal axis the position of the thermocouples from the outside $\left(T_{P C M 21}\right)$ to the center $\left(T_{P C M 26}\right)$ of the tank. The results are shown for row $2\left(\mathrm{PCM}_{2 \mathrm{j}}\right)$ which is at a mid-height of the tank and is consequently not influenced neither by the contact with air (row 1 ) nor by the PCM beneath the spiral coils (row 3 ).

During the preliminary melting $A \rightarrow B$, even if the initial temperatures are very similar ( $A$ curves), higher supply temperatures $\left(17^{\circ} \mathrm{C}\right.$ in Prep. 3 ) increase the heat transfer rate and consequently decrease the duration of the preparation. However, the PCM temperatures are less homogenous when the preparation is executed faster.

From $B$ to $C$, while the HTF was prepared, the PCM in the active region decreases its temperature by $3.1 \mathrm{~K}$ with preparation 1 , and by up to $4.7 \mathrm{~K}$ with preparation 3 (Table 3). In fact, given that the previous melting is faster with Prep. 3, not all the surrounding PCM had been melted and consequently the temperatures in C drop even below $8{ }^{\circ} \mathrm{C}$ (phase-change temperature), on the contrary to the first two preparations. This justifies the significant differences which are observed in terms of the energy gain during the solidification process $C \rightarrow D$.

During the $A \rightarrow B$ and the $C \rightarrow D$ process of Fig. 9, the thermocouple in TPсM24 seems to be located slightly further from the adjacent coils than thermocouple and consequently its thermal response is generally slower than in ТРСм23 or ТРСм25. 


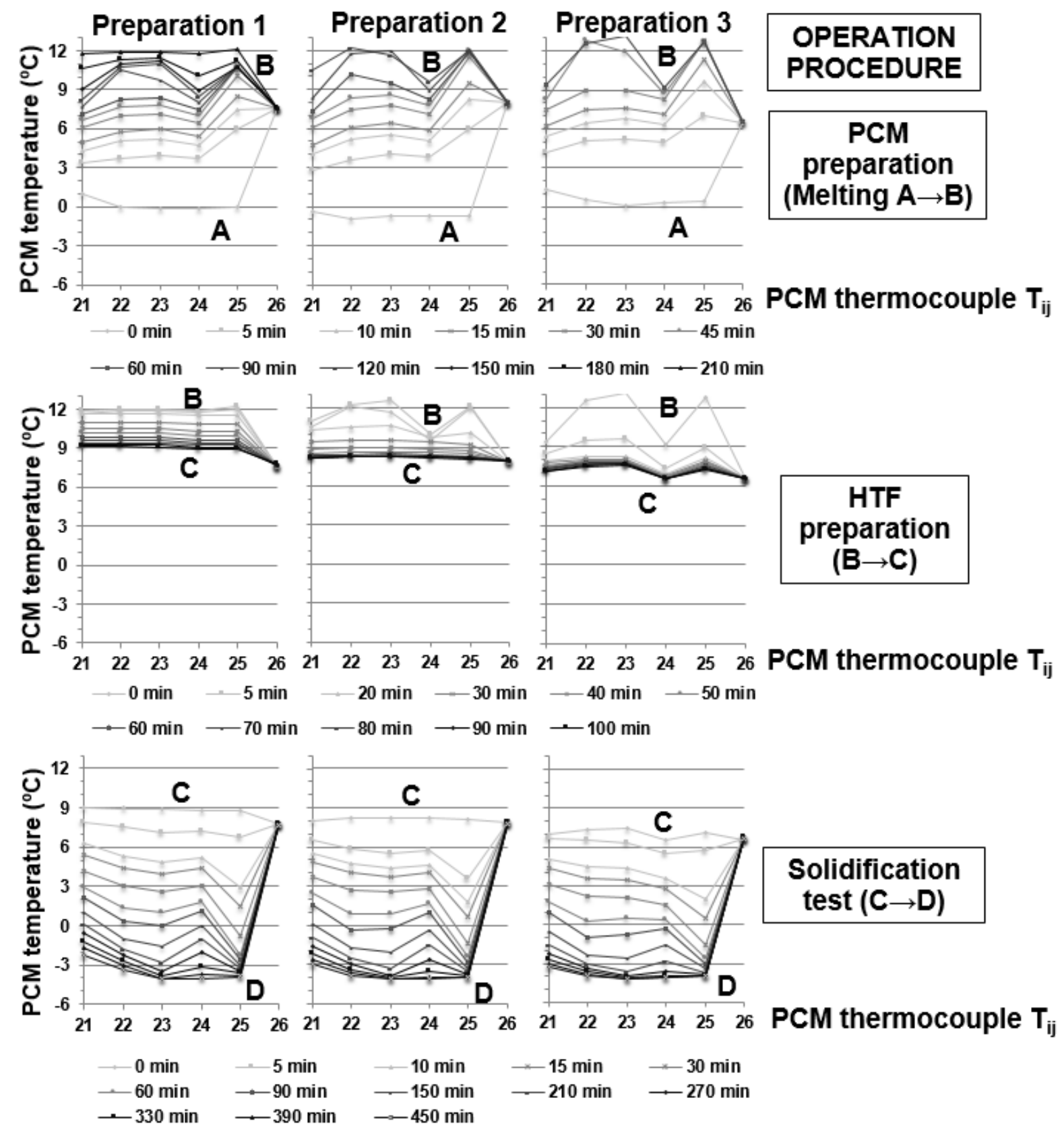

Fig. 9. PCM radial temperatures in the NRST tests

\subsection{Non reproducible melting tests (NRMT)}

The present section shows the results of 3 melting tests with identical operation conditions (supply temperature at $15^{\circ} \mathrm{C}$ with $2000 \mathrm{~kg} / \mathrm{h}$ ) but with a different preparation.

Fig. 10 illustrates how the tests were performed. Initially, in point $A$, the active PCM was at a mean temperature of $15^{\circ} \mathrm{C} \pm 0.5 \mathrm{~K}$. The following solidifications in $A \rightarrow B$ were performed with three different supply temperatures of $-2^{\circ} \mathrm{C}$ (Prep. 1), $-4^{\circ} \mathrm{C}$ (Prep. 2) and $-6^{\circ} \mathrm{C}$ (Prep. 3). The solidification process was stopped in point $\mathrm{B}$ once the mean $\mathrm{PCM}$ temperature in the active region reached $-0.5^{\circ} \mathrm{C} \pm 0.5 \mathrm{~K}$. Consequently, the main difference between the three tests is the heat transfer rate at which the previous solidification was carried out. During step $B \rightarrow C$ the tank is by-passed while the HTF 
wass heated up to the target of $15^{\circ} \mathrm{C}$. Once $15^{\circ} \mathrm{C}$ was reached, the melting process started (point $\mathrm{C}$ ) and finished when the active PCM had heated up to $15^{\circ} \mathrm{C} \pm 0.5 \mathrm{~K}$.

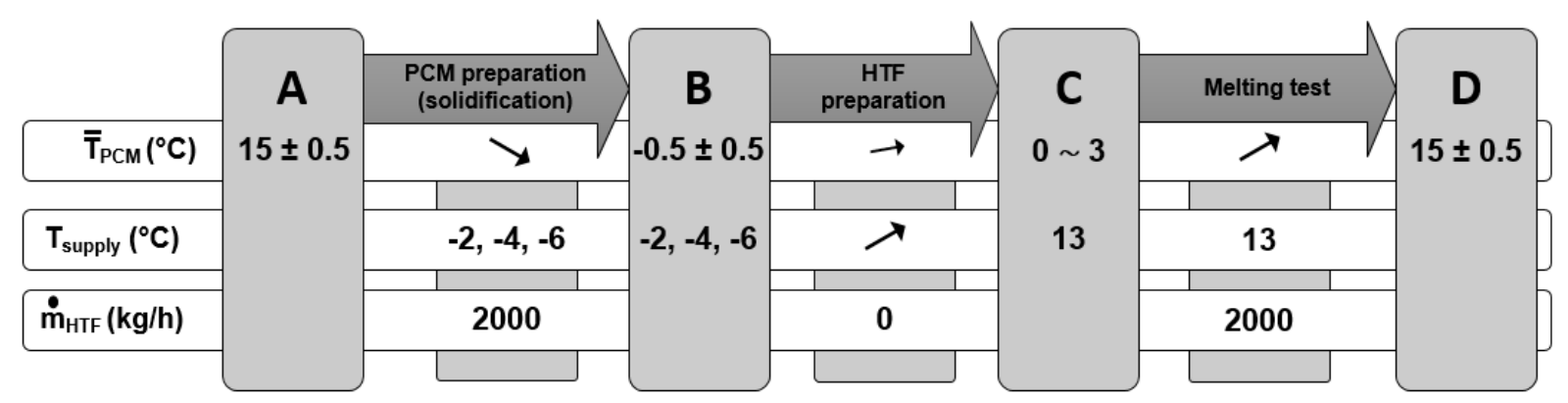

Fig. 10. Operation procedure in the NRMT tests

Table 4 shows the temperatures which are registered during the different steps of the NRMT tests. The most remarkable aspect is that the mean PCM temperature increase in step $B \rightarrow C$ was of $+0.8 \mathrm{~K}$ with Prep. 1 , and $+3.3 \mathrm{~K}$ with the fastest preparation (3). This can be explained mainly by the internal mass and energy transfer within the PCM, given that the tank is very well insulated and that the heat gain from the ambient is almost negligible within only one hour. As an indication, if the PCM is fully solid and the tank is by-passed, the measured PCM temperature increase during 3 days is of $0.06-0.1 \mathrm{~K} / \mathrm{h}$, so the temperature increase in $B \rightarrow C$ cannot be due to the heat gain from the ambient.

Fig. 11 illustrates the dynamic performance of the tank with respect to the energy transfer and to the mean PCM temperature in the active region. The time reference $(0$ minutes) has been chosen for the beginning of the melting process (point $C$ ). The solid lines represent the mean PCM temperature (left y-axis) and the dashed lines represent the energy exchange (right $y$-axis).

If only the melting tests are analysed $(C \rightarrow D)$, the first observation is that preparation 3 leads to a melting process which is $33 \%$ faster and with $29 \%$ less energy transfer. In fact, the previous solidification process $(A \rightarrow B)$ is $77 \%$ faster and with $33 \%$ less energy transfer. Consequently, the melting performance is directly related to the previous solidification process.

Table 4. Thermal history of the NRMT tests

\begin{tabular}{lcccc}
\hline Test & Measurement & Prep. 1 & Prep. 2 & Prep. 3 \\
\hline Point A & $\overline{\boldsymbol{T}}_{\boldsymbol{P C M}}\left({ }^{\circ} \mathbf{C}\right)$ & 14.77 & 15.20 & 14.91 \\
PCM preparation A $\rightarrow$ B & $\overline{\boldsymbol{T}}_{\text {Supply }}\left({ }^{\circ} \boldsymbol{C}\right)$ & -1.98 & -3.99 & -6.01 \\
Point B & $\overline{\boldsymbol{T}}_{\boldsymbol{P C M}}\left({ }^{\circ} \boldsymbol{C}\right)$ & -0.88 & -0.42 & -0.60 \\
\hline
\end{tabular}




\begin{tabular}{lcccc}
\hline Point C & $\overline{\boldsymbol{T}}_{\boldsymbol{P C M}}\left({ }^{\circ} \boldsymbol{C}\right)$ & -0.06 & 2.98 & 3.31 \\
Melting test C $\rightarrow$ D & $\overline{\boldsymbol{T}}_{\text {Supply }}\left({ }^{\circ} \boldsymbol{C}\right)$ & 15.28 & 15.10 & 14.74 \\
Point D & $\overline{\boldsymbol{T}}_{\boldsymbol{P C M}}\left({ }^{\circ} \boldsymbol{C}\right)$ & 14.86 & 15.19 & 15.04 \\
\hline
\end{tabular}

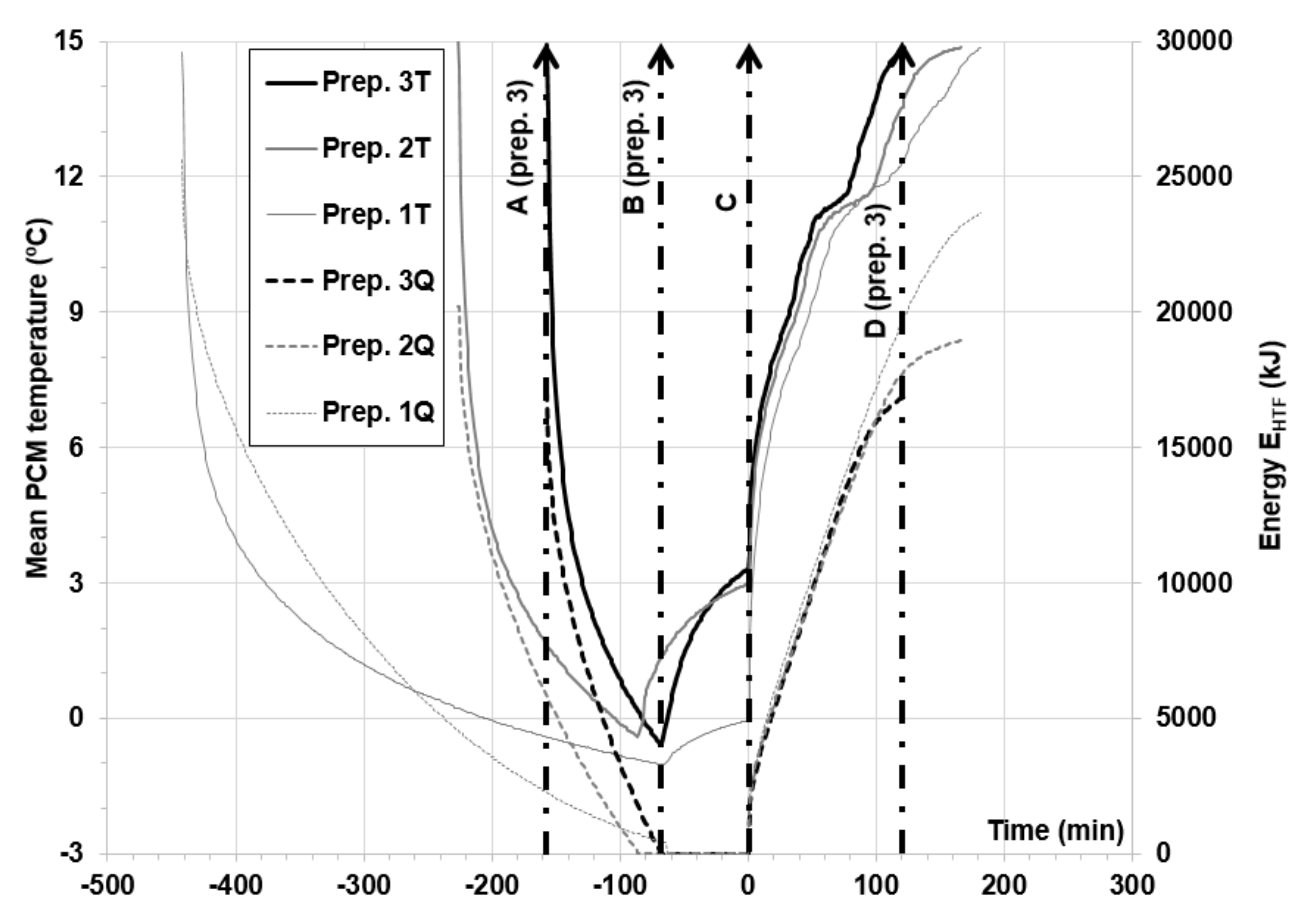

Fig. 11. PCM temperatures and energy transfer in the NRMT tests

Fig. 12 presents the horizontal temperature profiles of the PCM during the full thermal history of the NRMT tests. During the $A \rightarrow B$ solidification process, the center of the tank $\left(\mathrm{PCM}_{26}\right)$ reacts very slowly and does not even reach the phase-change temperature of $8^{\circ} \mathrm{C}$. On the contrary, after only 10 minutes all the rest of thermocouples are already below $8{ }^{\circ} \mathrm{C}$ and have started the phase-change. During $\mathrm{B} \rightarrow \mathrm{C}$ the tank is by-passed while the HTF is heated up to the target supply temperature of $15^{\circ} \mathrm{C}$. During this interval, the PCM temperatures are more constant for preparation 1, but they increase substantially $(+3.3 \mathrm{~K})$ with Prep. 3 due to the internal mass and energy transfer inside the tank.

The melting profiles $(C \rightarrow D)$ of the NRMT tests are all very similar in terms of trend. Nevertheless, the main difference is the time which is required for the active PCM thermocouples to reach $15^{\circ} \mathrm{C} \pm 0.5 \mathrm{~K}$. As explained previously, they are strictly related to the energy which has been exchanged during the preparation process $(A \rightarrow B)$. The faster the preparation, the less energy is transferred.

As explained before in the analysis of Fig. 9, thermocouple TРСм24 presents a slower response than the adjacent thermocouples, hereby supporting that it is probably located slightly further from the coils. 


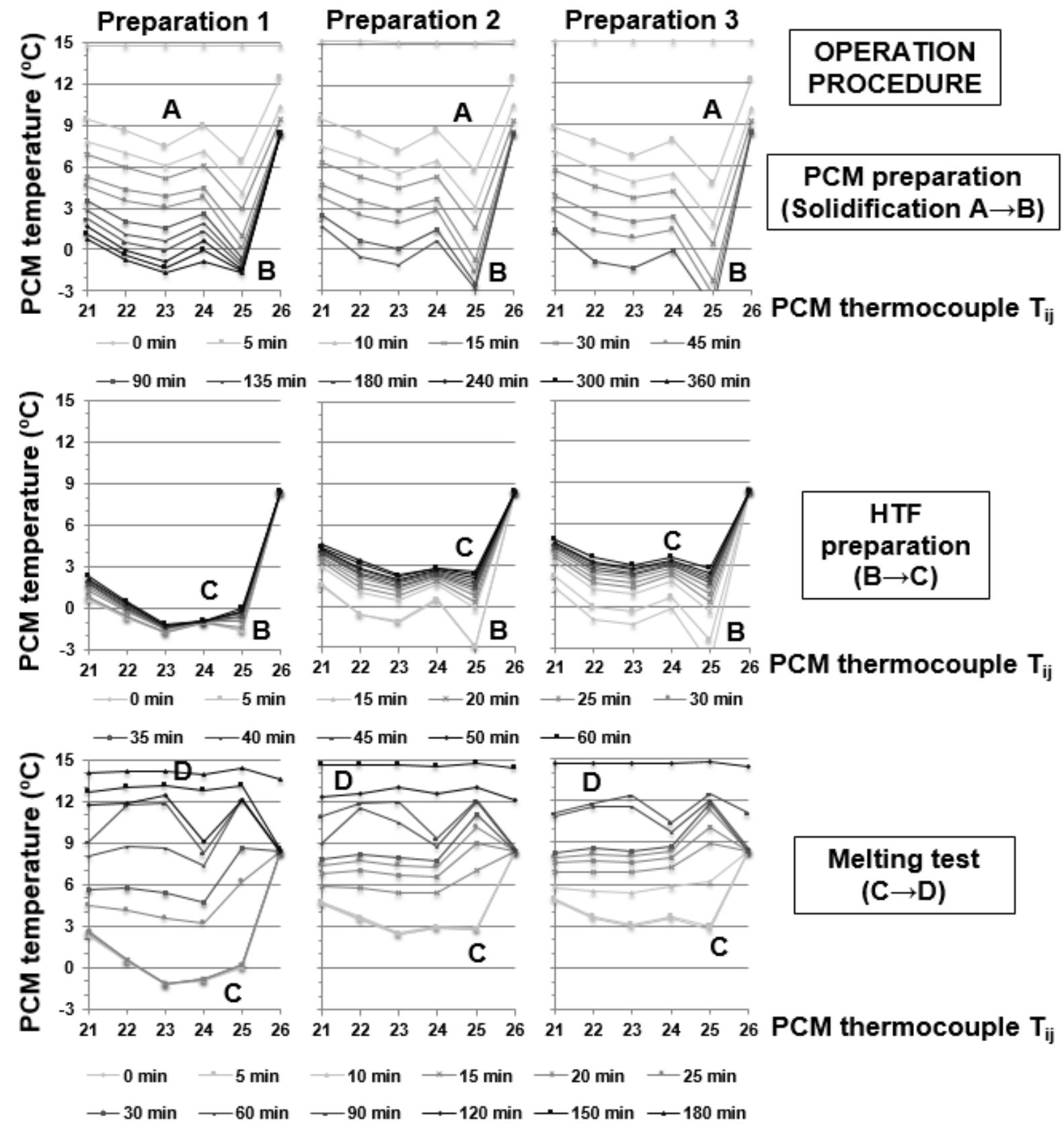

Fig. 12. PCM radial temperatures in the NRMT tests

\subsection{Discussion}

The previous results have shown that the initial state of a tank cannot be easily known or determined using PCM temperature sensors. The tested spiral coil concept, which is a low-cost solution and consequently attractive for industrial applications, has limitations from the point of view of the heat transfer with the PCM.

In principle, it is desirable to avoid dead regions and to have shorter distances than 3.7 $\mathrm{cm}$ from coil to coil. Nevertheless, given the maximum curvature of the copper tubes, it is inevitable to have a central region with less heat transfer surface using the present 
heat exchanger concept. Adding fins would increase the heat transfer with the PCM, but would reduce the main advantage of this heat exchanger concept which is adopting a low-cost solution.

The results indicate that the tested tank concept is particularly limited by the solidification process given the low thermal conductivity of the paraffin. From the strict point of view of the thermal performance, long charging periods are required in order to obtain more homogeneous PCM temperatures and to increase the thermal energy exchange with the heat transfer fluid during the following discharge process.

Dead regions inside the tank generally remain at the phase-change temperature of around $8^{\circ} \mathrm{C}$ and have a direct impact on the tank performance. When the active PCM regions are in the end of the latent heat transfer region, the dead areas can start to change phase and increase the thermal energy exchange. Consequently, to fix identical initial conditions it is necessary to measure the PCM temperatures in both active and dead regions and to leave sufficient time to reach a same internal PCM temperature distribution in the entire tank.

\section{Conclusions}

Low-cost thermal storage tank concepts are necessary to increase their market penetration in industrial cold storage applications. The present work analyses the experimental performance of a tank containing $181 \mathrm{~kg}$ of paraffin using a low-cost heat exchanger concept which is a set of 8 spiral-shaped coils.

In practical applications it is necessary to determine the operation strategies to ensure a proper use of the tank thermal storage capacity. Paraffins present a good thermodynamic behaviour after many cycles, so the scientific problem is how to determine the internal state of the tank and define the operation strategies. On a laboratory scale, this aspect can be studied by analysing the impact of the preparation of a tank on the following solidification or melting process. The following conclusions have been reached for the tested spiral-shaped coil concept:

- If the initial state of the tank is prepared and executed identically (supply temperature and mass flow rate), both the solidification and melting process are fully reproducible. The performance is practically identical both from the point of view of the PCM temperatures and of the exchanged thermal power. For instance, a maximum difference of $2 \%$ has been observed in the measured energy transfer.

- During the melting tests, the inversion of the PCM temperatures between the upper and lower regions is always observed due to the buoyancy effect. This inversion is fully reproducible and can be used as an indicator of the final part of the latent heat transfer process. When the liquid layer around the coils is sufficiently big, the blocks of solid paraffin detach and sink towards the bottom of the tank. Thus, if the vertical PCM temperatures are monitored, the inversion of temperatures indicate that the latent heat transfer region is reaching an end.

- The performance is not reproducible when preparing the PCM with a same initial mean temperature but with different heating/cooling rates. With faster preparations the PCM temperatures are initially less homogenous and a 
maximum reduction of $33 \%$ has been observed in the measured energy transfer. The PCM in the dead areas generally stays at the phase-change temperature but the energy which is transferred is not negligible and defines the initial state of the tank. Consequently, when working with LHS tanks with a significant amount of PCM (e.g. more than $100 \mathrm{~kg}$ ), if an experimental campaign is designed to study the impact of the operation conditions, the initial state of the tank has to be prepared considering both active and dead regions given their high impact on the performance.

As future work, the reproducibility of the tank performance will be studied with ice/water as phase-change material. This case presents more complex aspects given the random nucleation temperature. 


\section{Bibliography}

Azeldin El-Sawi, A., Haghighat, F., Akbari, H., 2014. Assessing long-term performance of centralized thermal energy storage system. Appl Therm Eng 62, 313-321.

Banaszek, J., Domañski, R., Rebow, M., El-Sagier, F., 1999. Experimental study of solid-liquid phase change in a spiral thermal energy storage unit. Appl Therm Eng 19,1253-1277.

Beghi, A., Cecchinato, L., Rampazzo, M., Simmini, F., 2014. Energy efficient control of HVAC systems with ice cold thermal energy storage. J Process Control 24, 773781.

Bruno, F., Tay, NHS., Belusko, M., 2014. Minimising energy usage for domestic cooling with off-peak PCM storage. Energy Build 76, 347-353.

Brousseau, P., Lacroix, M., 1996. Study of the thermal performance of a multi-layer PCM storage unit. Energy Convers Manage 37, 599-609.

Chua, KJ., Chou, SK., Yang, WM., Yan J., 2013. Achieving better energy-efficient air conditioning - A review of technologies and strategies. Appl Energy 104, 87-104.

Farid, MM., Khudhair, AM., Razack, SAK., Al-Hallaj S., 2004. A review on phase change energy storage: materials and applications. Energy Convers Manage 45, $1597-1615$.

Gil, A., Oró, E., Miró, L., Peiró, G., Ruiz, Á., Salmerón, JM. et al., 2014. Experimental analysis of hydroquinone used as phase change material (PCM) to be applied in solar cooling refrigeration. Int J Refrig 39; 95-103.

Kauffeld, M., Kawaji, M., Egolf, PW., 2005. Handbook on Ice Slurries: Fundamentals and Engineering, International Institute of Refrigeration, Paris.

Kauffeld, M., Wang, MJ., Goldstein, V., Kasza, KE., 2010. Ice slurry applications. Int J Refrig 33, 1491-1505.

López-Navarro, A., Biosca-Taronger, J., Corberán, JM., Peñalosa, C., Lázaro, A., Dolado, P. et al., 2014. Performance characterization of a PCM storage tank. Appl Energy 119, 151-162.

MacCracken, M., 2010. Energy storage providing for a low-carbon future. ASHRAE 45, 1643-1654.

Newsham, GR., Bowker, BG., 2010. The effect of utility time-varying pricing and load control strategies on residential summer peak electricity use, A review. Energy Policy 38, 3289-3296.

Oró, E., de Gracia, A., Castell, A., Farid, MM., Cabeza, LF., 2012. Review on phase change materials (PCMs) for cold thermal energy storage applications. Appl Energy 99, 513-533. 
Peñalosa, C., Lázaro, A., Delgado, M., Dolado, P., Zalba B., 2014. Valorization of a paraffin as low cost Phase Change Material. Characterization for using in Thermal Energy Storage, Eurotherm seminar 99.

Rismanchi, B., Saidur, R., BoroumandJazi, G., Ahmed, S., 2012. Energy, exergy and environmental analysis of cold thermal energy storage (CTES) systems. Renewable and Sustainable Energy Reviews 16, 5741-5746.

Rubitherm GmbH. Available at http://www.rubitherm.de, last accessed: 2014.

Saito, A., 2002. Recent advances in research on cold thermal energy storage. Int $\mathrm{J}$ Refrig 25, 177-189.

Saman, WY., 2013. Towards zero energy homes down under. Renewable Energy 49, 211-215.

Sehar, F., Rahman, S., Pipattanasomporn, M., 2012. Impacts of ice storage on electrical energy consumptions in office buildings. Energy Build 51, 255-262.

Shao, J., Darkwa, J., Kokogiannakis, G., 2015. Review of phase change emulsions (PCMEs) and their applications in HVAC systems. Energy Build 94, 200-217. ,

Tay, NHS., Belusko, M., Bruno, F., 2012. Experimental investigation of tubes in a phase change thermal energy storage system. Appl Energy 90, 288-297.

Yun, GY., Steemers, K., 2011. Behavioural, physical and socio-economic factors in household cooling energy consumption. Appl Energy 88, 2191-2200. 